\title{
A biblioteca universitária como mecanismo híbrido de geração de empreendimentos: possibilidades rumo à universidade empreendedora
}

\author{
Maísa Maryelli de Oliveira \\ Doutoranda; Universidade Federal de São Carlos, São Carlos, SP, Brasil; \\ marisoliveirafrazao@gmail.com \\ Camila Cassiavilani \\ Mestranda; Universidade Federal de São Carlos, São Carlos, SP, Brasil; \\ camilaca@ufscar.br \\ Adriana Tahereh Pereira Spinola \\ Doutoranda; Universidade Federal de São Carlos, São Carlos, SP, Brasil; \\ atpspinola@gmail.com \\ Roniberto Morato do Amaral \\ Doutor; Universidade Federal de São Carlos, São Carlos, SP, Brasil; \\ roniberto@ufscar.br

\section{Roberto Ferrari Júnior} \\ Doutor; Universidade Federal de São Carlos, São Carlos, SP, Brasil; \\ ferrari@ufscar.br
}

\begin{abstract}
Resumo: Este artigo discute potencialidades e dificuldades da biblioteca universitária como mecanismo híbrido de geração de empreendimentos, capaz de contribuir para a transição rumo à universidade empreendedora, entendida a partir de um modelo internacional. Tal discussão fundamenta-se na participação da Biblioteca Comunitária da Universidade Federal de São Carlos na primeira edição do Desafio UFSCar de Inovação e Empreendedorismo. Trata-se de um estudo exploratório, com abordagem qualitativa e procedimento de pesquisa documental. Embora a atuação da Biblioteca Comunitária no Desafio UFSCar tenha sido restrita à cessão de espaço físico, a experiência evidenciou que, com adequações na infraestrutura e gestão, ela pode incorporar elementos do coworking e laboratório de prototipagem, viabilizando a colaboração entre potenciais empreendedores, o networking e a apropriação de ferramentas e técnicas para a proposição de novos negócios. Além disso, os bibliotecários podem capacitar os futuros empreendedores no uso de bases de dados técnicocientíficas, especialmente as de patentes, viabilizando a busca de anterioridade, processos de inteligência competitiva e mapeamento tecnológico, considerados elementares na elaboração de um plano de negócios. Por ser, geralmente, um local de ampla circulação, a biblioteca também pode ajudar a disseminar uma cultura de inovação e empreendedorismo na universidade, o que favorece sua
\end{abstract}




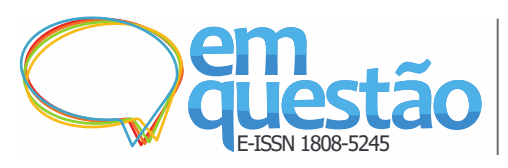

A biblioteca universitária como mecanismo híbrido de geração de empreendimentos: possibilidades rumo à universidade empreendedora

Maísa Maryelli de Oliveira, Camila Cassiavilani, Adriana Tahereh Pereira Spinola, Roniberto Morato do Amaral e Roberto Ferrari Junior

própria valorização e de seus profissionais no campus. Por outro lado, para que tudo isso aconteça, devem ser superadas eventuais dificuldades como: escassez de recursos financeiros e humanos; elaboração de uma política de uso dos espaços da biblioteca e resistência dos profissionais à mudança de cultura e à adoção de novas práticas.

Palavras-chave: Universidade empreendedora. Biblioteca universitária. Empreendedorismo acadêmico. Startup.

\section{Introdução}

Informação e conhecimento desempenham um papel central no atual padrão sócio-técnico-econômico dominante. Em um contexto de globalização, marcado pela celeridade com que mudam os mercados, os produtos, os processos, os modelos de negócio e as formas de organização, a capacidade de criar e absorver inovações é considerada um dos pilares da competitividade. Neste cenário profundamente dinâmico, também a universidade exerce um papel central, dado que a habilidade de aprender e capacitar-se continuamente é considerada elementar para profissionais, empresas e países que buscam converter conhecimento em fator de competitividade e se inserir na economia global.

Historicamente, a universidade surgiu com a missão de ensinar e vivenciou duas significativas revoluções. Na primeira delas, teve a pesquisa agregada à sua missão e, na segunda, passou a ter como prioridade, também, o desenvolvimento econômico e social. Foi no contexto desta última revolução que surgiu o conceito de "universidade empreendedora", caracterizada pelo ambiente propício à inovação e pela capacidade de definir estratégias para transformar o conhecimento em valor econômico e social (ETZKOWITZ, 1998). Clark (1998, 2003) a define como uma instituição ativa na adoção de contínuas mudanças estruturais e em seu modo de responder às demandas internas e externas, capaz de empreender, criar e inovar.

O padrão competitivo capitalista demanda da instituição de ensino superior (IES) a habilidade de se manter constantemente atualizada, principalmente considerando o caráter interativo e localizado do aprendizado e 

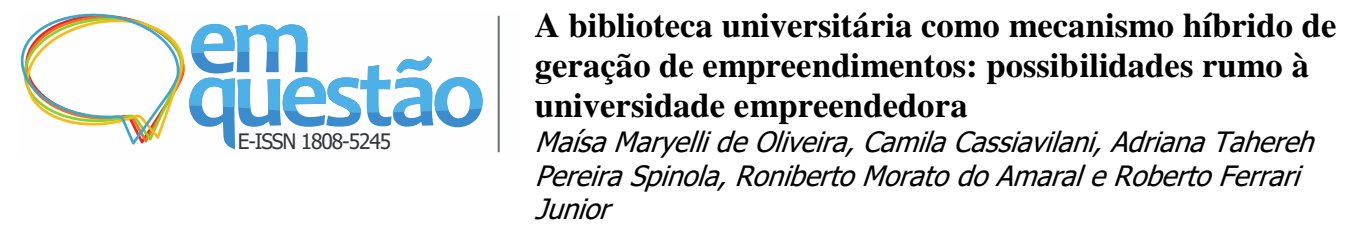

da inovação (LASTRES; FERRAZ, 1999). Tendo em vista sua missão de desenvolver uma cultura empreendedora integrada - representada por uma visão compartilhada, que gere uma perspectiva institucional orientada para responder satisfatoriamente às demandas sociais -, a universidade deve ser capaz de revisar suas políticas, ações e espaços continuamente (AUDY, 2011).

Neste contexto, destacamos a necessidade de repensar a atuação da biblioteca universitária (BU), considerando seu potencial de estímulo à inovação e ao empreendedorismo entre a comunidade acadêmica e, consequentemente, de suporte à transição para a universidade empreendedora. Essa abordagem se faz relevante, sobretudo porque, na literatura nacional e estrangeira, as discussões sobre BU e inovação concentram-se, frequentemente, nas inovações em gestão (HARRIS, 2006; YEH; WALTER, 2016) e em serviços de informação (DYSART; JONES, 2011; ZANINELLI; NOGUEIRA; PERES, 2019), raramente focando a possibilidade de a BU atuar ativamente na promoção da inovação e do empreendedorismo.

No Brasil, foi publicado o Decreto $\mathrm{n}^{\circ}$ 9.283, de 7 de fevereiro de 2018, que regulamenta o Marco Legal de Ciência, Tecnologia e Inovação (CT\&I), autorizando universidades a criarem ambientes promotores da inovação, seja através de ecossistemas de inovação, seja através de mecanismos de geração de empreendimentos (BRASIL, 2018). Essa regulamentação abre caminho para que novas atribuições sejam assumidas e consolidadas pela BU e por seus profissionais.

Dada a escassez de estudos sobre a BU como promotora da inovação e do empreendedorismo e as incipientes discussões e possibilidades trazidas pela regulamentação do Marco Legal de CT\&I, este artigo discute potencialidades e dificuldades da biblioteca universitária como mecanismo híbrido de geração de empreendimentos, capaz de contribuir para a transição rumo à universidade empreendedora, entendida a partir de um modelo de ações proposto por Jansen e colaboradores (2015). Tal discussão fundamenta-se na participação da Biblioteca Comunitária (BCo) da Universidade Federal de São Carlos (UFSCar) na primeira edição do Desafio UFSCar de Inovação e Empreendedorismo. 

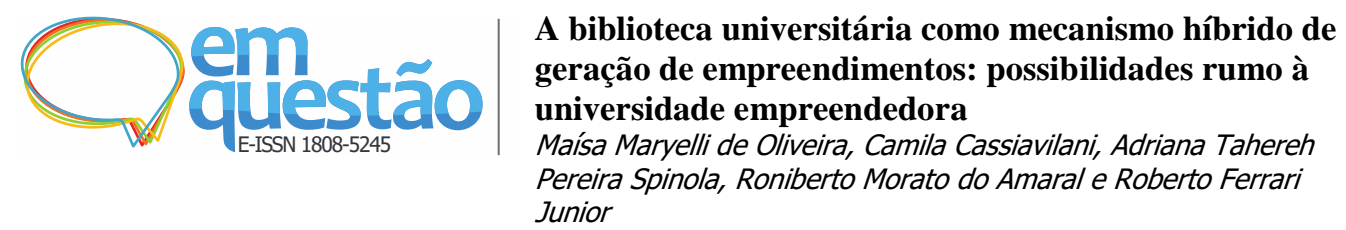

Na seção seguinte, apresentamos uma revisão da literatura, na qual localizamos o papel da universidade empreendedora nos arranjos e dinâmicas que promovem o desenvolvimento socioeconômico de um país. Abordamos como o Marco Legal de CT\&I trata a questão da criação de ambientes promotores da inovação pelas universidades brasileiras e o que entende por mecanismos de geração de empreendimentos (BRASIL, 2018). Trazemos um panorama sobre esses mecanismos, resgatando conceitos e definições de incubadora, aceleradora, coworking e laboratório aberto de prototipagem de produtos e processos / makerspace / fab lab, evidenciando que tais mecanismos têm se tornado cada vez mais conjugados e sobrepostos.

\section{Marco Legal de CT\&I e os mecanismos de geração de empreendimentos}

A virada do século XX para o XXI foi marcada pela inauguração de um novo padrão de desenvolvimento econômico e social, resumido na expressão "economia baseada no conhecimento", criada em referência à dependência crescente do conhecimento e da informação e do alto nível de especialização, observados na maioria das economias avançadas (ORGANISATION FOR ECONOMIC CO-OPERATION AND DEVELOPMENT, 1996). Nesta nova economia, a inovação desempenha papel central. Estudiosos como Freeman (2011) chamam a atenção para a importância das inovações incrementais e do ambiente institucional para o desenvolvimento econômico, percebido como um processo evolucionário.

O que o autor busca enfatizar, assim como Nelson (2011), é que a invenção, a inovação e a acumulação tecnológica decorrem de um processo social, que tem como responsáveis não apenas o empresário e a firma - como sugeria Schumpeter (1997) -, mas diferentes instituições e atores, dentro de uma dinâmica compreendida a partir do conceito de Sistema Nacional de Inovação. Caracterizado pelas redes de inter-relações institucionais que contribuem para gerar inovação nas empresas - seja ela mercadológica ou organizacional, de produto ou de processo -, tal sistema se constitui a partir das interações entre os 


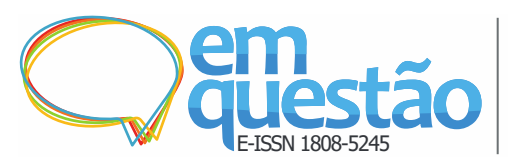

A biblioteca universitária como mecanismo híbrido de geração de empreendimentos: possibilidades rumo à universidade empreendedora

Maísa Maryelli de Oliveira, Camila Cassiavilani, Adriana Tahereh Pereira Spinola, Roniberto Morato do Amaral e Roberto Ferrari Junior

setores público e privado e os sistemas financeiro e de educação e formação de recursos humanos.

Já o modelo da Tripla Hélice (Triple Helix), também uma abordagem não linear ou interativa, vincula a inovação aos arranjos institucionais entre universidade, empresa e governo - as três hélices de uma espiral caracterizada pelas constantes reconfigurações das comunicações, redes e organizações, em uma dinâmica na qual as próprias hélices se transformam continuamente, devido às mudanças do ambiente (ETZKOWITZ, 1998). A compreensão desses modelos, arranjos e processos sociais contextualiza a importância das universidades dentro da dinâmica que leva à inovação e lança luz sobre a necessidade de essas instituições se transformarem, a fim de que sejam capazes de propor soluções para problemas cada vez mais complexos.

Segundo Etzkowitz (1998), a maioria dos países estaria buscando conformar esse tipo de arranjo institucional, a fim de fortalecer seu ambiente inovador. Nesse modelo da Tripla Hélice, além das missões de ensino e pesquisa, a universidade pauta o desenvolvimento econômico e social de onde atua, estimulando o surgimento de ambientes de inovação e disseminando uma cultura empreendedora (AUDY, 2011).

Em consonância com essa nova missão atribuída à universidade, o Decreto $\mathrm{n}^{\circ}$ 9.283, de 7 de fevereiro de 2018 , que regulamenta o novo Marco Legal de CT\&I (Lei 13.243/16) no Brasil, autoriza que instituições científicas, tecnológicas e de inovação (ICT) públicas se tornem sócias minoritárias de empresas cuja atividade principal seja a inovação; criem fundos mútuos de investimentos nessas empresas e apoiem a criação, implantação e consolidação de ambientes promotores da inovação. O documento define o que são esses ambientes e quais são suas dimensões:

Art. $2^{\circ}[\ldots]$

II - ambientes promotores da inovação [grifo nosso] - espaços propícios à inovação e ao empreendedorismo, que constituem ambientes característicos da economia baseada no conhecimento, articulam as empresas, os diferentes níveis de governo, as Instituições Científicas, Tecnológicas e de Inovação, as agências de fomento ou organizações da sociedade civil, e envolvem duas dimensões: 

geração de empreendimentos: possibilidades rumo à universidade empreendedora

Maísa Maryelli de Oliveira, Camila Cassiavilani, Adriana Tahereh Pereira Spinola, Roniberto Morato do Amaral e Roberto Ferrari Junior

a) ecossistemas de inovação [grifo nosso] - espaços que agregam infraestrutura e arranjos institucionais e culturais, que atraem empreendedores e recursos financeiros, constituem lugares que potencializam o desenvolvimento da sociedade do conhecimento e compreendem, entre outros, parques científicos e tecnológicos, cidades inteligentes, distritos de inovação e polos tecnológicos; e

b) mecanismos de geração de empreendimentos [grifo nosso] mecanismos promotores de empreendimentos inovadores e de apoio ao desenvolvimento de empresas nascentes de base tecnológica, que envolvem negócios inovadores, baseados em diferenciais tecnológicos e buscam a solução de problemas ou desafios sociais e ambientais, oferecem suporte para transformar ideias em empreendimentos de sucesso, e compreendem, entre outros, incubadoras de empresas, aceleradoras de negócios, espaços abertos de trabalho cooperativo e laboratórios abertos de prototipagem de produtos e processos; [...] (BRASIL, 2018).

O decreto estimula, portanto, a criação de ambientes promotores de inovação a fim de facilitar, cada vez mais, a interação entre os principais atores responsáveis pela inovação no país. Como esquematizado na Figura 1, nesses ambientes estão contidas duas dimensões: os ecossistemas de inovação e os mecanismos de geração de empreendimentos ${ }^{1}$. As discussões deste artigo se concentram nesta última dimensão, na qual entendemos que a BU pode estar situada, considerando seu potencial - evidenciado na seção de discussão - para apoiar o surgimento de empreendimentos inovadores de base tecnológica e para, assim, auxiliar na conformação da universidade empreendedora.

Figura 1 - Esquema representativo dos ambientes promotores de inovação e suas dimensões

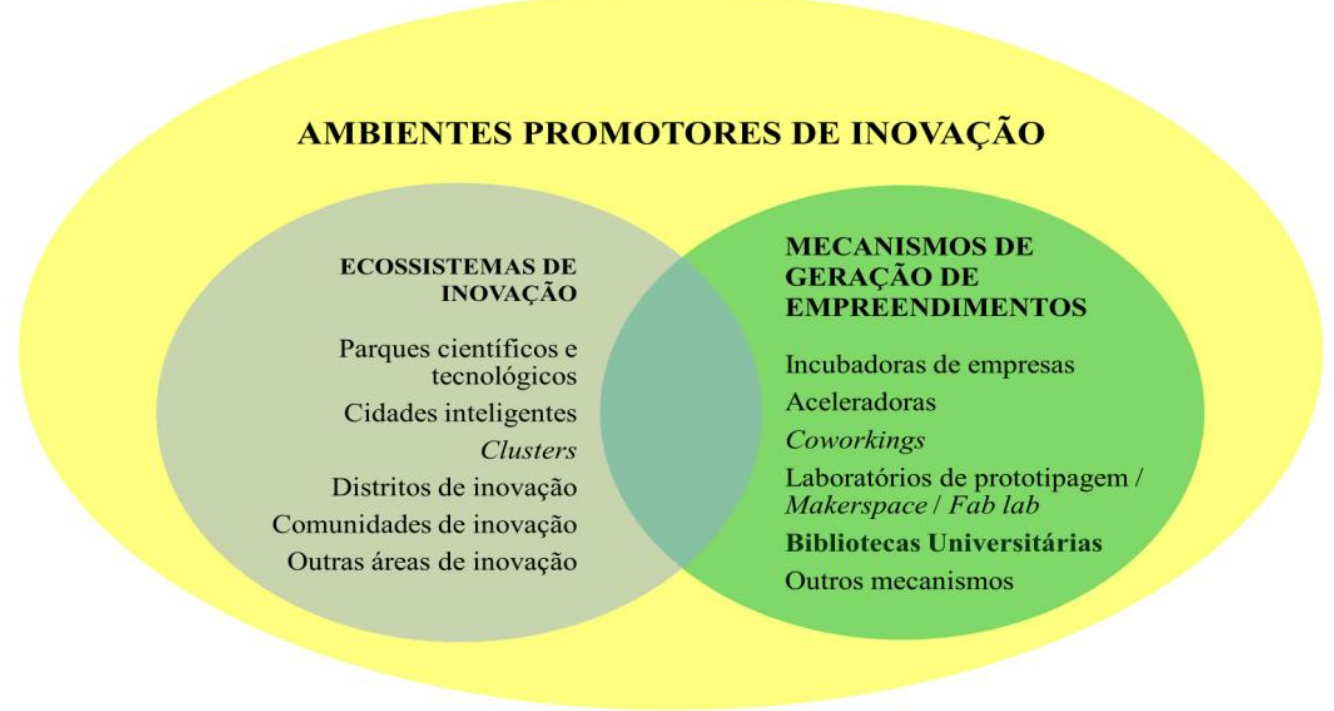

Fonte: Adaptado de Aranha (2016, p. 7). 

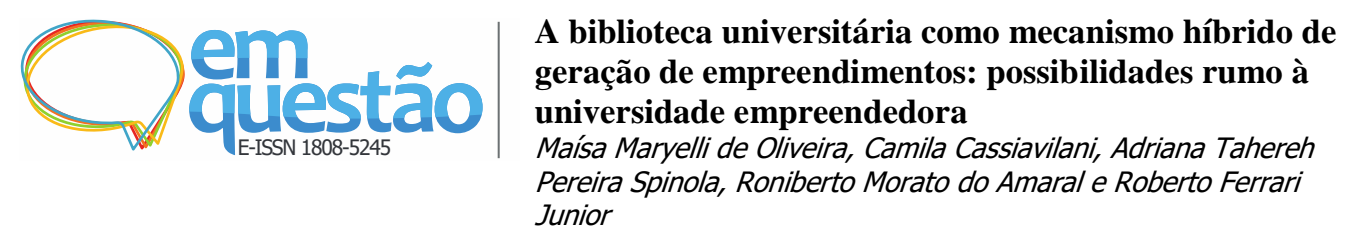

As dinâmicas e modelos de geração de empreendimentos estão mudando no Brasil e no mundo, com a incorporação de novos atores aos processos e com o surgimento de modelos híbridos de incubação ${ }^{2}$. Na esteira das transformações, a pré-incubação de empresas passa a ocorrer em espaços como laboratórios de instituições de pesquisa e laboratórios de prototipagem - fab labs e makerspaces. Já os processos de incubação passam a ser observados, também, em coworkings e aceleradoras, por exemplo (ARANHA, 2016).

Observa-se, portanto, que a fronteira entre os diferentes mecanismos está se tornando difusa ou mesmo inexistente. É nesse contexto que emerge a possibilidade de a BU atuar como um mecanismo de geração de empreendimentos, de modo híbrido, combinando elementos e ações tradicionalmente associados a incubadoras, aceleradoras, coworkings e laboratórios de prototipagem. Cabe, aqui, pontuar que a Lei $\mathrm{n}^{\circ} 13.243$, de 11 de janeiro de 2016 - que alterou a Lei $\mathrm{n}^{\circ}$ 10.973, de 2 de dezembro de 2004, conhecida como Lei de Inovação Tecnológica - define incubadora de empresas como "[...] uma organização ou estrutura que objetiva estimular ou prestar apoio logístico, gerencial e tecnológico ao empreendedorismo inovador e intensivo em conhecimento [...]" (BRASIL, 2016).

Conforme esclarece Aranha (2016, p. 10), "O processo linear de incubação, com critérios de seleção, tipos de apoio e graduação, com três distintas fases: pré-incubação, incubação e pós-graduação [...]" passou por mudanças. Em um contexto marcado pela celeridade nas transformações na tecnociência e pela necessidade de gerar empresas de rápido crescimento, o processo de incubação se tornou mais fluido e dinâmico. Ao mesmo tempo, emergiram novos mecanismos de apoio ao empreendedorismo inovador, dentre os quais as aceleradoras e coworkings, que também exercem atividades de incubação.

A missão principal das aceleradoras, porém, é dar tração a negócios geralmente bem preparados e altamente escaláveis -, levando-os a um patamar que possibilite a atração de investimentos de capital de risco. Elas oferecem programas de aceleração e mentorias com empreendedores de sucesso e congregam em seu entorno, além dos empreendedores (novatos e já 

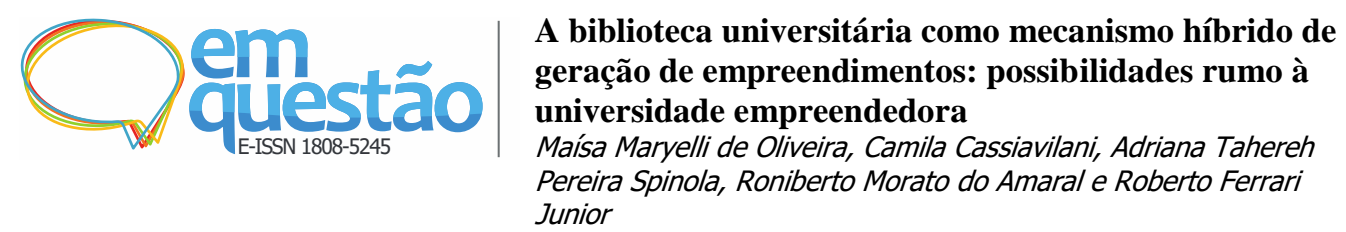

experientes), pesquisadores, empresários e investidores. Ao buscar capital, como frisa Aranha (2016), as empresas em aceleração devem estar preparadas para entrar no mercado, ou seja, devem ser capazes de ir além do foco inicial nos ajustes técnicos em seu produto ou serviço.

Já o coworking, conceitualmente, tornou-se popular como um sistema de trabalho no qual profissionais de diferentes áreas, empresas e instituições compartilham o mesmo espaço, dividindo as despesas do local. Entretanto, já se compreende que "[...] o coworking vai muito além de se configurar apenas como um espaço físico compartilhado, caracterizando-se como um lugar onde os profissionais podem criar novas redes e interagir com as mais variadas áreas." (MEDINA; KRAWULSKI, 2015, p. 187).

Segundo Mesquita (2016, p. 14), trata-se de “[...] um novo ecossistema social e econômico, construído a partir do desenvolvimento de laços afetivos e da inteligência coletiva." No contexto das empresas nascentes, o coworking pode até mesmo envolver processos semelhantes aos das incubadoras e aceleradoras:

Existem coworkings com regras de seleção de candidatos, tempo de permanência, ambientes de negócios, espaços comuns, programas de capacitação, foco no tipo de empresa e sinergia com as outras empresas do gênero. (ARANHA, 2016, p.17).

Ao lado das incubadoras, aceleradoras e coworkings, os makerspaces (em português, espaços “maker") e os fab labs (abreviação em inglês para laboratórios de fabricação), ou laboratórios abertos de prototipagem de produtos e processos (termo usado no Decreto $\mathrm{n}^{\circ}$ 9.283, de 7 de fevereiro de 2018, que regulamenta o Marco Legal de CT\&I), também são considerados mecanismos de geração de empreendimentos. Esses espaços são desdobramentos do que ficou conhecido como "movimento maker" ou "cultura maker", caracterizados por atividades "mão na massa", a partir da apropriação de ferramentas e equipamentos de eletrônica, mecânica, robótica e de técnicas não digitais, como marcenaria e artesanato, com a finalidade de solucionar um problema, de desenvolver um protótipo ou de criar um negócio. 


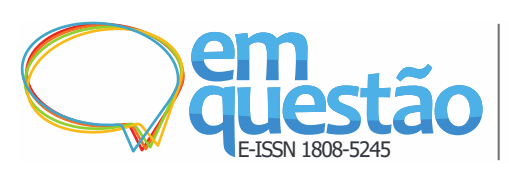

A biblioteca universitária como mecanismo híbrido de geração de empreendimentos: possibilidades rumo à universidade empreendedora

Maísa Maryelli de Oliveira, Camila Cassiavilani, Adriana Tahereh Pereira Spinola, Roniberto Morato do Amaral e Roberto Ferrari Junior

O primeiro fab lab surgiu no Massachusetts Institute of Technology (MIT), nos Estados Unidos, em 2001. Hoje, a Fab Foundation, derivada dessa experiência, conta com uma rede de centenas de fab labs espalhados pelo mundo. Eles seguem um padrão que envolve a utilização de equipamentos específicos - como impressora 3D, máquina de fresagem $\mathrm{CNC}^{3}$ (Computer Numerical Control), circuito de produção, corte a laser/gravura, fresagem de precisão e vinil plotter -, a abertura gratuita do espaço para uso da comunidade e o compartilhamento de conhecimento entre os labs integrantes da rede (PINTO et al., 2018).

Como pontuam Eychenne e Neves (2013), os fab labs devem ser um organismo ativo, voltado à aprendizagem prática da tecnologia (o fazer) na criação de protótipos. Além disso, devem privilegiar abordagens colaborativas e transdisciplinares, respondendo aos problemas e questões locais com soluções inovadoras e ajudando a incubar empresas, através da facilitação de processos.

O resgate de conceitos e de definições de incubadora, aceleradora, coworking e laboratório aberto de prototipagem de produtos e processos / makerspace / fab lab dá a dimensão de como os mecanismos de geração de empreendimentos têm se tornado cada vez mais conjugados e sobrepostos. Tal constatação fundamenta toda a discussão deste artigo, no qual defendemos que a BU pode ser um mecanismo híbrido de geração de empreendimentos, capaz de contribuir para a conformação da universidade empreendedora.

\section{Metodologia}

$\mathrm{Na}$ tentativa de avaliar essa potencial contribuição da BU e identificar as dificuldades a serem superadas para tornar essa contribuição uma realidade, fizemos um estudo exploratório. Estudos dessa natureza são considerados ideais quando se trata de um tema pouco abordado e podem constituir a primeira etapa de uma investigação mais ampla. Esse tipo de pesquisa caracteriza-se por " [...] proporcionar visão geral, de tipo aproximativo, acerca de determinado fato." (GIL, 2010, p. 27). Assim, apresentamos uma discussão introdutória, reflexiva, passível de aprofundamento por meio de novas pesquisas. 


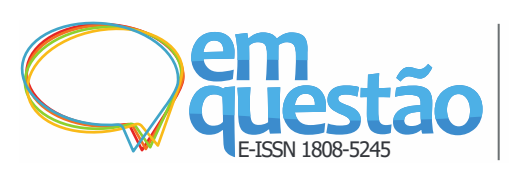

\begin{abstract}
A biblioteca universitária como mecanismo híbrido de geração de empreendimentos: possibilidades rumo à universidade empreendedora

Maísa Maryelli de Oliveira, Camila Cassiavilani, Adriana Tahereh Pereira Spinola, Roniberto Morato do Amaral e Roberto Ferrari Junior
\end{abstract}

A abordagem adotada foi qualitativa, com procedimento de pesquisa documental, tendo como fontes de informação os canais institucionais online da universidade (website da instituição ${ }^{4}$, Rádio UFSCar, boletim eletrônico InfoRede, Diário da Reitoria) e da Agência de Inovação da UFSCar ${ }^{5}$ (website, Facebook e página oficial do desafio), além do Relatório Anual de Atividades da IES, de 2018. Recorremos à técnica de análise de conteúdo (BARDIN, 1977) para estabelecer potenciais correlações entre o material coletado e o modelo de ações para a conformação da universidade empreendedora proposto por Jansen e colaboradores (2015).

Elaborado a partir de estudos de casos em instituições de diferentes regiões do mundo que são referência em empreendedorismo - o Massachusetts Institute of Technology (MIT - Estados Unidos), o International Institute of Technology Hyderabad (IIIT - Índia) e a Universidade de Utrecht (Holanda) -, o modelo, como mostra a Figura 2, é constituído por 15 ações distribuídas por três estágios:
a) educação;
b) estímulo;
c) incubação.

Segundo os autores, esse conjunto de ações pode ajudar as universidades a construir um ambiente que encoraje os alunos a empreender - abrindo o próprio negócio - e a seguir carreira como empreendedores após a conclusão de seus cursos de graduação.

A escolha do referido modelo deveu-se justamente ao seu foco em ações e estágios, em vez de uma determinação a priori sobre um ou outro mecanismo mais adequado para se chegar à universidade empreendedora. Entendemos, assim, que o modelo vai ao encontro da noção de que os diferentes mecanismos se tornam cada vez mais híbridos. 


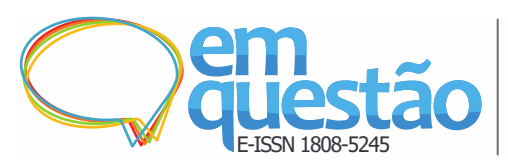

A biblioteca universitária como mecanismo híbrido de geração de empreendimentos: possibilidades rumo à universidade empreendedora

Maísa Maryelli de Oliveira, Camila Cassiavilani, Adriana Tahereh Pereira Spinola, Roniberto Morato do Amaral e Roberto Ferrari Junior

Figura 2 - Modelo de ações de incentivo ao empreendedorismo na universidade

\section{UNIVERSIDADE EMPREENDEDORA}

\begin{tabular}{|c|c|c|}
\hline Estágio um: Educação & Estágio dois: Estímulo & Estágio três: Incubação \\
\hline $\begin{array}{l}\text { 1. Oferecer pessoal de apoio } \\
\text { e facilidades }\end{array}$ & $\begin{array}{l}\text { 1. Apoiar a formação de } \\
\text { equipes }\end{array}$ & $\begin{array}{l}\text { 1. Encontrar e trabalhar com } \\
\text { outros empreendedores }\end{array}$ \\
\hline $\begin{array}{l}\text { 2. Destacar modelos e } \\
\text { histórias de sucesso }\end{array}$ & $\begin{array}{l}\text { 2. Oferecer mecanismos para } \\
\text { a validação de ideias }\end{array}$ & $\begin{array}{l}\text { 2. Oferecer espaço de } \\
\text { trabalho }\end{array}$ \\
\hline \multirow{5}{*}{$\begin{array}{l}\text { 3. Oferecer cursos } \\
\text { introdutórios de } \\
\text { empreendedorismo }\end{array}$} & $\begin{array}{l}\text { 3. Oferecer oportunidades de } \\
\text { pitching }\end{array}$ & $\begin{array}{l}\text { 3. Oferecer mentorias a } \\
\text { startups }\end{array}$ \\
\hline & $\begin{array}{l}\text { 4. Apoiar a criação de planos } \\
\text { de negócios }\end{array}$ & $\begin{array}{l}\text { 4. Oferecer oportunidades de } \\
\text { networking }\end{array}$ \\
\hline & \multirow{3}{*}{$\begin{array}{l}\text { 5. Possibilitar o } \\
\text { desenvolvimento de } \\
\text { protótipos }\end{array}$} & $\begin{array}{l}\text { 5. Organizar competições de } \\
\text { planos de negócios }\end{array}$ \\
\hline & & $\begin{array}{l}\text { 6. Estabelecer programas de } \\
\text { aceleração }\end{array}$ \\
\hline & & 7. Oferecer financiamento \\
\hline $\begin{array}{l}\text { Acordar } \\
\text { empreendedores } \\
\text { dormentes }\end{array}$ & $\begin{array}{l}\text { Apoiar o processo da } \\
\text { ideia ao plano de } \\
\text { negócios }\end{array}$ & $\begin{array}{l}\text { Incubar as empresas } \\
\text { nascentes até que elas } \\
\text { possam sobreviver } \\
\text { independentemente }\end{array}$ \\
\hline
\end{tabular}

Fonte: Adaptado de Jansen e colaboradores (2015, p. 172, tradução nossa).

\section{Discussão de resultados}

Nesta seção, são apresentados e discutidos os resultados na pesquisa, em três tópicos. Inicialmente, trazemos uma descrição geral da primeira edição do Desafio UFSCar de Inovação e Empreendedorismo. No segundo tópico, abordamos a participação da BCo da UFSCar na iniciativa. Finalmente, no terceiro tópico, discutimos as dificuldades e potencialidades da biblioteca universitária como mecanismo híbrido de geração de empreendimentos, observadas a partir do desafio.

\subsection{Desafio UFSCar de Inovação e Empreendedorismo}

Realizado pela Agência de Inovação da UFSCar em parceria com o Sistema Integrado de Bibliotecas da UFSCar (SIBi-UFSCar), o Desafio UFSCar de Inovação e Empreendedorismo teve sua primeira edição entre outubro de 2017 e junho de 2018. A iniciativa objetivou, principalmente, prospectar e apoiar projetos inovadores resultantes de estudos e pesquisas; capacitar alunos, 


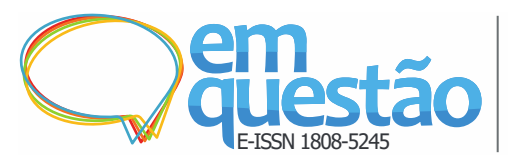

A biblioteca universitária como mecanismo híbrido de geração de empreendimentos: possibilidades rumo à universidade empreendedora

Maísa Maryelli de Oliveira, Camila Cassiavilani, Adriana Tahereh Pereira Spinola, Roniberto Morato do Amaral e Roberto Ferrari Junior

docentes, servidores técnico-administrativos e participantes externos com vínculo com a universidade para inovar, empreender e transformar a sociedade; oferecer mecanismos de apoio à geração e viabilização dos empreendimentos e disseminar a cultura de inovação e empreendedorismo.

Os participantes puderam inscrever seus trabalhos em quatro modalidades: novos empreendimentos inovadores; trabalhos baseados em tecnologias protegidas da UFSCar ainda não licenciadas; resultados de atividades acadêmicas e pesquisas com resultados passíveis de proteção da propriedade intelectual. No total, foram 90 equipes inscritas, somando 241 pessoas, entre pesquisadores e alunos da própria UFSCar e integrantes externos, de outras instituições de ensino, empresas e sociedade.

O desafio foi dividido em quatro fases:

a) Fase um: inscriçõos;

b) Fase dois: construção e submissão de modelo de negócios simplificado;

c) Fase três: elaboração de teste de conceito e plano de negócios;

d) Fase quatro: articulação de parcerias, captação de recursos e apresentação final do projeto.

Concluído todo o processo, duas iniciativas foram premiadas, uma na categoria "licenciamento" e outra na categoria "startup". Ambos os vencedores apresentaram soluções que envolviam a aplicação de materiais para a área da Saúde ${ }^{6}$. Como premiação, foram oferecidos um pacote de serviços da Amazon no valor de cinco mil dólares, três meses de acomodação no Onovolab (campus de inovação independente situado em São Carlos, SP), três meses de capacitação no programa da Fast Track Ventures em parceira com a empresa S2IT e uma bolsa do Programa Integrado de Capacitação em Finanças do Serviço Brasileiro de Apoio às Micro e Pequenas Empresas (SEBRAE), além de um troféu entregue pela reitoria da UFSCar.

As premiações visaram estimular e fornecer condições iniciais para a incubação das startups. Todavia, para além de apontar vencedores, a iniciativa buscou promover experiências que contribuíssem para a autonomia dos potenciais empreendedores, a fim de que conseguissem seguir com seus projetos 

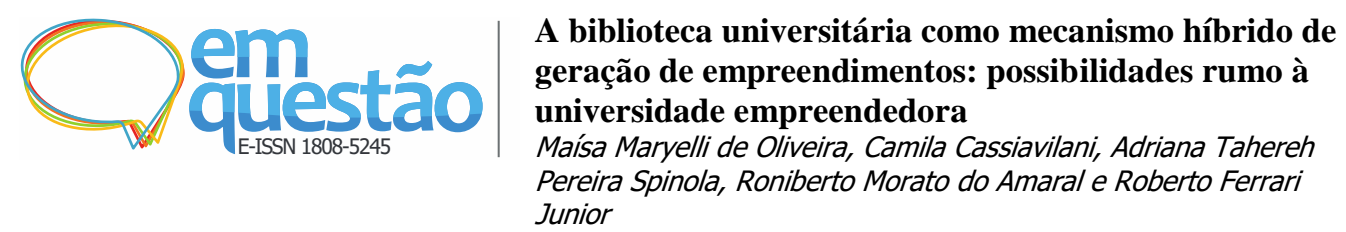

e empreendimentos após a conclusão do desafio. Para tanto, diferentemente do observado nas competições de negócios em geral, que se caracterizam pela curta duração (um dia ou um final de semana) e pelo foco na premiação e em que os participantes chegam para competição com seus planos prontos, o Desafio UFSCar de Inovação e Empreendedorismo teve uma extensa programação, incluindo atividades de capacitação, mentorias, networking e conexão com o mercado, em um processo de preparação que durou quatro meses.

A Biblioteca Comunitária da UFSCar foi palco de ações em todas as fases do desafio. A seguir, apresentamos as atividades realizadas, relacionandoas com os diferentes estágios e ações do modelo de Jansen e colaboradores (2015) (Figura 2).

\subsection{A Biblioteca Comunitária da UFSCar no Desafio UFSCar de Inovação e}

\section{Empreendedorismo}

Localizada na região central do campus São Carlos, SP, a BCo da UFSCar está instalada em um complexo de nove mil metros quadrados, cujo prédio principal tem cinco pisos, por onde circulam diariamente cerca de 2.500 visitantes. $\mathrm{Na}$ fase um, a BCo sediou palestras com foco na sensibilização de potenciais participantes do desafio. Além disso, serviu como ponto de apoio para o esclarecimento de dúvidas e realização de inscrições.

$\mathrm{Na}$ fase dois, a biblioteca recebeu os participantes para uma maratona de capacitação denominada "Canvathon", com duração de três horas, na qual as equipes construíram seu Canvas, um modelo simplificado de negócios. Para isso, contaram com a ajuda de mentores do meio empresarial. Nesta etapa, todo o segundo piso da BCo, com mais de 40 mesas e 150 cadeiras, foi reservado para uso - por uma noite - como espaço compartilhado de trabalho, voltado à interação entre os participantes, à troca de ideias e à discussão e ao amadurecimento dos projetos de inovação inscritos no desafio. A maratona foi precedida por uma palestra de esclarecimento sobre a metodologia Canvas.

A fase três consistiu em um período de aproximadamente três meses de capacitação das equipes na elaboração de seu plano de negócios e na validação de ideias no mercado. Para tanto, utilizou-se, principalmente, uma plataforma 

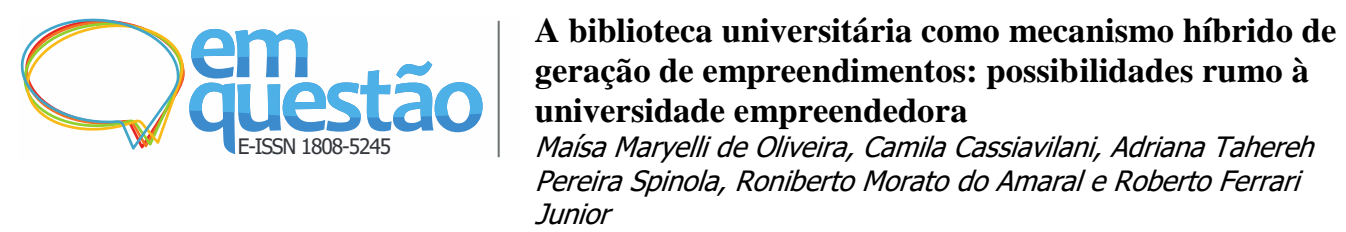

virtual com vídeos produzidos pela Agência de Inovação da UFSCar sobre plano de marketing, MVP (Minimum Viable Product), planejamento financeiro, propriedade intelectual, pitch, entre outros temas. As equipes que prosseguiram nesta fase receberam mentorias individuais com profissionais do mercado, as quais também ocuparam o espaço da BCo. Uma sala foi disponibilizada exclusivamente para esse fim, sendo sinalizada com um banner da Agência de Inovação. Mais de 50 mentorias foram realizadas no local, ao longo de duas semanas.

Por fim, a fase quatro estimulou a integração das equipes com o ecossistema de inovação de São Carlos e nacional, reunindo empresários, instituições de fomento e investidores. As equipes que avançaram no desafio com a entrega de seus planos de negócios e apresentações de pitch tiveram a oportunidade de participar de uma rodada de apresentações para investidoresanjo e investidores de venture capital em Araraquara (SP). Além disso, na final do desafio, realizada na UFSCar, campus São Carlos, estiveram presentes outros potenciais investidores, empresários e representantes de instituições de fomento como a Financiadora de Estudos e Projetos (FINEP) e a Desenvolve SP Agência de Desenvolvimento Paulista.

No Quadro 1, correlacionamos as diferentes fases e atividades do Desafio UFSCar de Inovação e Empreendedorismo (distinguindo aquelas realizadas na $\mathrm{BCo}$ ) e os estágios e ações do modelo de Jansen e colaboradores (2015) para a conformação de uma universidade empreendedora. Assim, evidenciamos que, na realização do desafio, foram desempenhadas 14 das 15 ações de educação, estímulo e incubação propostas no modelo, com exceção apenas da ação de estabelecer programas de aceleração (sexta atividade do estágio três - Figura 2).

Cabe destacar que as ações não aconteceram de modo linear, como se educação e estímulo levassem, naturalmente, à incubação. A fase três do desafio, por exemplo, incluiu ações dos estágios um (educação) e dois (estímulo) do modelo de Jansen e colaboradores (2015). 
A biblioteca universitária como mecanismo híbrido de geração de empreendimentos: possibilidades rumo à universidade empreendedora

Maísa Maryelli de Oliveira, Camila Cassiavilani, Adriana Tahereh Pereira Spinola, Roniberto Morato do Amaral e Roberto Ferrari Junior

Quadro 1 - Correlação entre o Desafio UFSCar de Inovação e Empreendedorismo e o modelo de universidade empreendedora de Jansen e colaboradores (2015)

\begin{tabular}{|c|c|c|c|}
\hline $\begin{array}{l}\text { Fase do } \\
\text { Desafio } \\
\text { UFSCar }\end{array}$ & $\begin{array}{c}\text { Atividade do Desafio } \\
\text { UFSCar } \\
\text { (*) Atividade realizada na BCo }\end{array}$ & $\begin{array}{c}\text { Estágio do } \\
\text { modelo de Jansen e } \\
\text { colaboradores (2015) } \\
\text { - universidade } \\
\text { empreendedora }\end{array}$ & $\begin{array}{c}\text { Ação do } \\
\text { modelo de Jansen } \\
\text { e colaboradores } \\
(\mathbf{2 0 1 5 )}- \\
\text { universidade } \\
\text { empreendedora } \\
\end{array}$ \\
\hline \multirow{2}{*}{$\begin{array}{l}\text { Fase um: } \\
\text { Inscrições }\end{array}$} & \multirow{2}{*}{$\begin{array}{l}\text { Palestras de estímulo a } \\
\text { empreendedores* }\end{array}$} & \multirow{2}{*}{$\begin{array}{c}\text { Estágio } \\
\text { um: Educação } \\
\text { Acordar } \\
\text { empreendedores } \\
\text { dormentes }\end{array}$} & $\begin{array}{l}\text { Oferecer pessoal } \\
\text { de apoio e } \\
\text { facilidades }\end{array}$ \\
\hline & & & $\begin{array}{c}\text { Destacar modelos e } \\
\text { histórias de } \\
\text { sucesso } \\
\end{array}$ \\
\hline \multirow{2}{*}{$\begin{array}{l}\text { Fase dois: } \\
\text { Validação } \\
\text { da ideia }\end{array}$} & $\begin{array}{l}\text { Construção de modelo } \\
\text { simplificado de negócio* }\end{array}$ & \multirow{2}{*}{$\begin{array}{c}\text { Estágio } \\
\text { dois: Estímulo } \\
\text { Apoiar o processo da } \\
\text { ideia ao } \\
\text { desenvolvimento do } \\
\text { plano de negócios }\end{array}$} & $\begin{array}{c}\text { Oferecer } \\
\text { mecanismos para a } \\
\text { validação de ideias } \\
\end{array}$ \\
\hline & $\begin{array}{l}\text { Encontros para apoio à } \\
\text { formação de equipes }\end{array}$ & & $\begin{array}{c}\text { Apoiar a formação } \\
\text { de equipes }\end{array}$ \\
\hline \multirow{4}{*}{$\begin{array}{c}\text { Fase três: } \\
\text { Capacitação, } \\
\text { elaboração } \\
\text { de teste de } \\
\text { conceito e } \\
\text { plano de } \\
\text { negócios }\end{array}$} & $\begin{array}{l}\text { Curso introdutório ao } \\
\text { empreendedorismo }\end{array}$ & $\begin{array}{c}\text { Estágio } \\
\text { um: Educação } \\
\text { Acordar } \\
\text { empreendedores } \\
\text { dormentes } \\
\end{array}$ & $\begin{array}{l}\text { Oferecer cursos } \\
\text { introdutórios de } \\
\text { empreendedorismo }\end{array}$ \\
\hline & $\begin{array}{c}\text { Curso e evento de } \\
\text { apresentações de pitch* }\end{array}$ & \multirow{3}{*}{$\begin{array}{c}\text { Estágio } \\
\text { dois: Estímulo } \\
\text { Apoiar o processo da } \\
\text { ideia ao } \\
\text { desenvolvimento do } \\
\text { plano de negócios }\end{array}$} & $\begin{array}{c}\text { Oferecer } \\
\text { oportunidades de } \\
\text { pitching }\end{array}$ \\
\hline & $\begin{array}{l}\text { Curso e mentorias para plano } \\
\text { de negócios* }\end{array}$ & & $\begin{array}{l}\text { Apoiar a criação de } \\
\text { planos de negócios }\end{array}$ \\
\hline & $\begin{array}{c}\text { Mentorias e networking } \\
\text { voltados à elaboração de } \\
\text { protótipos* }\end{array}$ & & $\begin{array}{c}\text { Possibilitar o } \\
\text { desenvolvimento } \\
\text { de protótipos } \\
\end{array}$ \\
\hline \multirow{4}{*}{$\begin{array}{c}\text { Fase } \\
\text { quatro: } \\
\text { Parcerias, } \\
\text { captação de } \\
\text { recursos e } \\
\text { apresentação } \\
\text { final do } \\
\text { projeto }\end{array}$} & $\begin{array}{l}\text { Apresentação de pitch para } \\
\text { investidores-anjo e } \\
\text { investidores de venture capital } \\
\text { e para instituições } \\
\text { governamentais de fomento* }\end{array}$ & $\begin{array}{c}\text { Estágio } \\
\text { três: Incubação } \\
\text { Incubar as empresas } \\
\text { nascentes até que elas } \\
\text { possam sobreviver } \\
\text { independentemente } \\
\end{array}$ & $\begin{array}{c}\text { Oferecer } \\
\text { financiamento }\end{array}$ \\
\hline & $\begin{array}{l}\text { Apresentação de pitch para } \\
\text { potenciais parcerias com } \\
\text { empresários* }\end{array}$ & $\begin{array}{c}\text { Estágio } \\
\text { três: Incubação } \\
\text { Incubar as empresas } \\
\text { nascentes até que elas } \\
\text { possam sobreviver } \\
\text { independentemente }\end{array}$ & $\begin{array}{l}\text { Oferecer } \\
\text { oportunidade de } \\
\text { networking }\end{array}$ \\
\hline & $\begin{array}{l}\text { Apresentação das equipes do } \\
\text { desafio para escolha do melhor } \\
\text { plano de negócios e pitch }\end{array}$ & $\begin{array}{c}\text { Estágio } \\
\text { três: Incubação } \\
\text { Incubar as empresas } \\
\text { nascentes até que elas } \\
\text { possam sobreviver } \\
\text { independentemente }\end{array}$ & $\begin{array}{c}\text { Organizar } \\
\text { competição de } \\
\text { plano de negócios }\end{array}$ \\
\hline & $\begin{array}{l}\text { Premiação aos vencedores: } \\
\text { três meses em um espaço de }\end{array}$ & $\begin{array}{c}\text { Estágio } \\
\text { três: Incubação }\end{array}$ & $\begin{array}{l}\text { Encontrar outros } \\
\text { empreendedores e }\end{array}$ \\
\hline
\end{tabular}




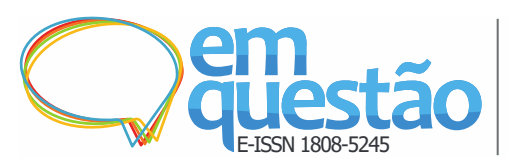

A biblioteca universitária como mecanismo híbrido de geração de empreendimentos: possibilidades rumo à universidade empreendedora

Maísa Maryelli de Oliveira, Camila Cassiavilani, Adriana Tahereh Pereira Spinola, Roniberto Morato do Amaral e Roberto Ferrari Junior

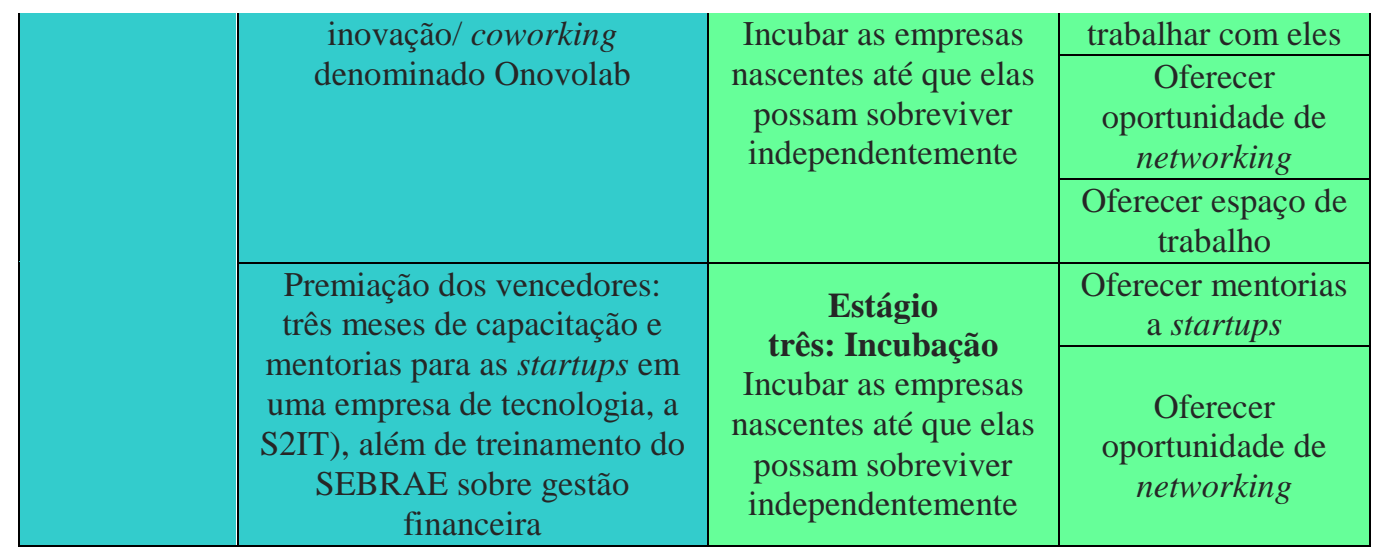

Fonte: Elaborado pelos autores, com base em Jansen e colaboradores (2015).

Consideramos, a partir da síntese apresentada no Quadro 1, que o desafio foi capaz de despertar empreendedores dormentes, capacitá-los e apoiá-los do processo da ideia ao plano de negócios. Avaliamos, também, que o desafio, apesar de não ser um programa permanente da UFSCar e de não oferecer a quantidade de recursos que uma incubadora de empresas geralmente oferece, promoveu, especialmente na fase quatro, algumas ações para que os empreendimentos nascentes pudessem sobreviver de forma independente após o encerramento do desafio.

Entre tais ações, destaca-se o encontro dos empreendedores com investidores-anjo e investidores de venture capital, com instituições governamentais de fomento e com empresários, que teve a finalidade de ensejar a obtenção de financiamento e o networking, por exemplo. Sobretudo no contexto da UFSCar, que não tem uma incubadora de empresas própria, tais ações podem ser decisivas para a vitalidade dos negócios nascentes.

Sobre a atuação da $\mathrm{BCo}$, especificamente, entendemos que se restringiu à cessão de espaço físico para a realização de diferentes ações do desafio. De toda forma, a experiência trouxe a perspectiva de que a BU e seu conjunto de recursos - físicos, informacionais e humanos - podem ser um mecanismo híbrido de geração de empreendimentos, capaz de servir às ações de todas as fases do modelo de Jansen e colaboradores (2015). Para isso, porém, algumas dificuldades ainda devem ser superadas. A seguir, discutimos potencialidades e dificuldades percebidas no contexto da BCo da UFSCar, mas que podem inspirar outras bibliotecas universitárias a refletirem sobre como incorporar a 


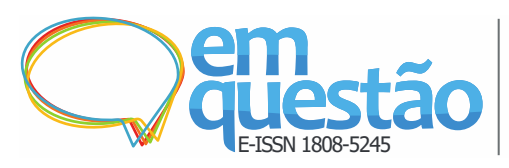

A biblioteca universitária como mecanismo híbrido de geração de empreendimentos: possibilidades rumo à universidade empreendedora

Maísa Maryelli de Oliveira, Camila Cassiavilani, Adriana Tahereh Pereira Spinola, Roniberto Morato do Amaral e Roberto Ferrari Junior

missão de ajudar suas universidades a se tornarem empreendedoras, gerando empreendimentos inovadores.

\subsection{Dificuldades e potencialidades da biblioteca universitária como} mecanismo de geração de empreendimentos

$\mathrm{O}$ uso do espaço físico da BCo da UFSCar em atividades de incentivo à inovação e ao empreendedorismo, assim como o desafio, por si só, pode ser percebido como um passo em direção à constituição da universidade empreendedora. Isso porque a biblioteca - além de ser um espaço de convivência, de interação e de compartilhamento de recursos informacionais e de ambientes de estudo, de leitura, de cultura e de lazer - situa-se na região central do campus São Carlos, recebendo cerca de 2.500 visitantes por dia. Dessa forma, as atividades ali realizadas têm grande visibilidade, o que favorece a disseminação de uma cultura de inovação e empreendedorismo entre a comunidade acadêmica.

No desafio, a BCo acolheu cursos, palestras e mentorias e serviu de espaço de trabalho compartilhado na ocasião em que as equipes criaram seus planos de negócios e seus protótipos. As atividades tiveram curta duração e os ambientes não foram planejados para tais usos, com a incorporação de ferramentas e equipamentos para a construção dos protótipos, por exemplo. Contudo, a experiência indicou que, com as devidas adequações em termos de infraestrutura e gestão, a biblioteca pode incorporar elementos do coworking e do laboratório de prototipagem / makerspace / fab lab, a fim de proporcionar aos potenciais empreendedores benefícios como colaboração, networking e a apropriação de ferramentas, equipamentos e técnicas para a solução de problemas e proposição de novos negócios.

Tal contexto sugere que "A biblioteca como um depósito de informações é um conceito ultrapassado. A biblioteca do século XXI é uma oficina comunitária, um centro cheio de ferramentas da economia do conhecimento." (RESNICK, 2014, tradução nossa) ${ }^{7}$. Ao discutir o futuro das BUs, Bonte (2015) frisa que elas não podem ser apenas “armazéns de livros”. Diante do cenário de novas demandas dos usuários, o autor sugere que sejam criados ambientes mais 

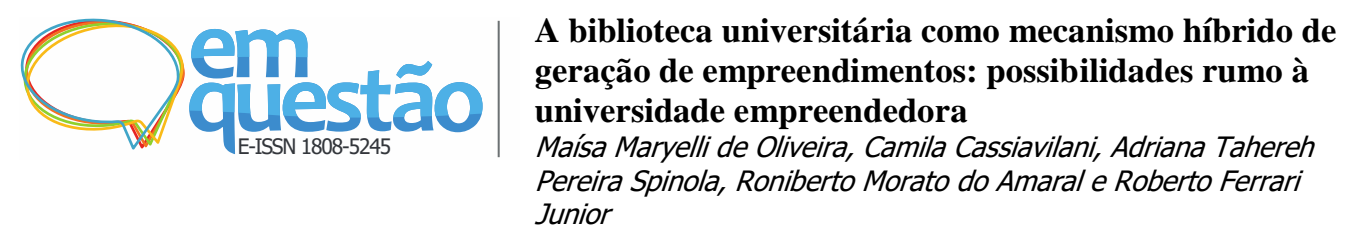

convidativos e que sejam pensadas maneiras de promover a aprendizagem social. Katsirikou e Sefertzi (2000), por sua vez, ressaltam que para engajar, antecipar e promover a inovação, a biblioteca deve aprender a mudar e o bibliotecário deve aprender a aprender.

A incorporação de elementos do coworking na BU, como destacam Schopfel, Roche e Hubert (2015), além de servir de estímulo à inovação e ao empreendedorismo no meio acadêmico, pode contribuir para o reposicionamento e valorização da própria biblioteca e de seus profissionais no campus. Contudo, a atribuição desses novos usos aos espaços físicos da biblioteca - a qual pode servir às ações de estímulo, educação e incubação do modelo de Jansen e colaboradores (2015) - esbarra em uma série de obstáculos. Um deles é a própria disponibilidade de espaço. Esse não é um problema para a BCo, pois seu prédio possui áreas livres para readequação, mas certamente a situação não é a mesma em todas as bibliotecas universitárias.

$\mathrm{O}$ redesenho dos ambientes também pode envolver custos relativos à contratação de profissionais, ao projeto arquitetônico e de interiores e à aquisição de mobiliário, de ferramentas e de equipamentos de eletrônica, mecânica e robótica, bem como de itens de marcenaria e artesanato. No contexto de bibliotecas universitárias públicas, como a da UFSCar, nem sempre há disponibilidade de recursos orçamentários para projetos como esse.

A mudança implica, ainda, a elaboração de uma política de uso desses espaços, com normas e critérios sobre quem poderá utilizá-los; sobre por quanto tempo eles poderão ser ocupados; sobre como funcionarão as áreas comuns, os ambientes de negócios e os programas de capacitação; sobre se eles terão foco em um determinado tipo de empreendimento e sobre se receberão empresas externas à universidade, por exemplo.

O próprio Decreto $\mathrm{n}^{\circ}$ 9.283, de 7 de fevereiro de 2018, que regulamenta o Marco Legal de CT\&I no país, embora autorize as universidades públicas a apoiarem a criação, implantação e consolidação de ambientes promotores da inovação, dentre os quais os mecanismos de geração de empreendimentos, não apresenta orientações sobre como isso deve ocorrer. Cada instituição deve 

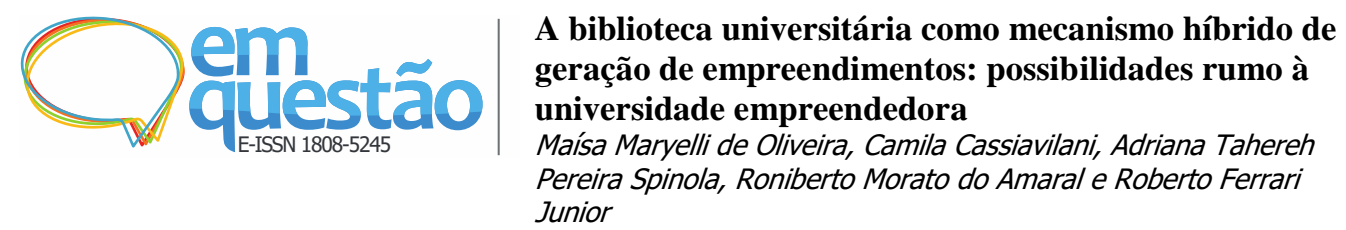

estabelecer regulamentações internas com base nas mudanças, aberturas e compreensões trazidas pelo Marco Legal da CT\&I.

A BCo também dispõe de recursos informacionais como bases de dados de conteúdo técnico-científico, especialmente as bases de dados de patentes. Como sugerem Hoppenfeld e Malafi (2015), bibliotecários e cientistas da informação poderiam colaborar na capacitação de futuros empreendedores no uso dessas bases, viabilizando a busca de anterioridade e auxiliando no processo de inteligência competitiva e no de mapeamento tecnológico, procedimentos considerados elementares na elaboração de um plano de negócios. Tais ações iriam ao encontro do que Jansen e colaboradores (2015, p. 172) recomendam no estágio um de seu modelo: "oferecer pessoal de apoio e facilidades". Os profissionais da BCo poderiam, ainda, colaborar na organização de eventos, como cursos, competições de planos de negócios e demais inciativas semelhantes ao desafio.

O problema é que fatores externos, relativos à administração e ao aspecto financeiro, por exemplo, exercem controle sobre a biblioteca, limitando a inovação (JANTZ, 2012). No desafio, as ações de apoio às equipes foram idealizadas e executadas pela Agência de Inovação da UFSCar, sem a participação dos profissionais da BCo. Conforme sugere Clark (1998, 2003), entende-se que essa articulação entre diferentes atores é necessária para a transição rumo à universidade empreendedora. Contudo, a biblioteca ainda precisa encontrar maneiras de incorporar os profissionais no processo de mudança cultural, superando o fato de que "[...] não são todos os colaboradores que compreendem a necessidade de inovação e como ela afeta a criação de valor [...]" nesses ambientes (ZANINELLI; NOGUEIRA; PERES, 2019, p. 4).

Avaliamos, portanto, que é necessária uma maior aproximação entre as lideranças e os profissionais da Agência de Inovação e da BU. Além disso, são necessários investimentos na oferta de capacitações, de cursos e de treinamentos para que os bibliotecários tenham consciência de sua importância na promoção da inovação e do empreendedorismo na universidade e, também, para que eles tenham domínio de estudos métricos, de redação e análise de patentes e das 


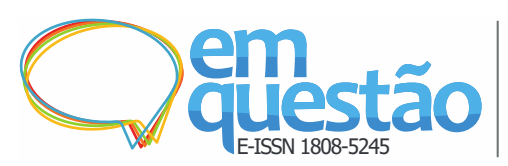

A biblioteca universitária como mecanismo híbrido de geração de empreendimentos: possibilidades rumo à universidade empreendedora

Maísa Maryelli de Oliveira, Camila Cassiavilani, Adriana Tahereh Pereira Spinola, Roniberto Morato do Amaral e Roberto Ferrari Junior

demais informações úteis à elaboração de planos de negócios, estando aptos a auxiliar os potenciais empreendedores.

\section{Considerações finais}

A análise da participação da BCo no Desafio UFSCar de Inovação e Empreendedorismo evidenciou que a BU pode se tornar um ator ativo na promoção da inovação e do empreendedorismo entre a comunidade acadêmica, contribuindo com ações de estímulo, educação e incubação para tornar a universidade empreendedora. Nesse sentido, este artigo tem como uma de suas principais contribuições a compreensão de que a BU pode assumir essa nova função, posicionando-se como um mecanismo híbrido de geração de empreendimentos, combinando elementos e ações tradicionalmente associados às incubadoras, às aceleradoras, ao coworking e aos laboratórios de prototipagem.

Atuando de forma híbrida, a BU dará à comunidade de potenciais empreendedores a possibilidade de desfrutar de um conjunto de benefícios associados aos diferentes mecanismos de geração de empreendimentos, tais como: colaboração, networking e apropriação de ferramentas e técnicas para a solução de problemas e proposição de novos negócios.

Neste artigo, também identificamos um diferencial da BU com relação aos demais mecanismos, que potencializa sua ação. Os bibliotecários, sabendo usar fontes de informação, podem oferecer serviços de recuperação, além da capacitação dos futuros empreendedores no uso de bases de dados técnicocientíficas, especialmente as bases de patentes, que viabilizam a busca de anterioridade e processos de inteligência competitiva e de mapeamento tecnológico, considerados elementares na elaboração de um plano de negócios.

A experiência da BCo no desafio, embora tenha ficado restrita à cessão de espaço físico, também indicou que a biblioteca, por ser um local de ampla circulação, pode servir como vitrine, ajudando a disseminar uma cultura de inovação e empreendedorismo na universidade, o que favorece a valorização dela mesma e de seus profissionais no campus. Avaliamos que, no caso da BCo 

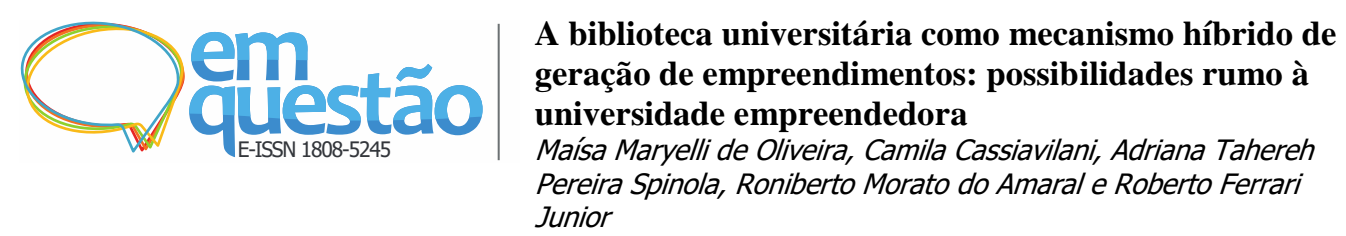

da UFSCar, o passo seguinte é implantar espaços com ações permanentes, de modo que a biblioteca consolide sua atuação como mecanismo de geração de empreendimentos. Ao mesmo tempo, devem-se buscar formas de estender o projeto aos demais campi da UFSCar, em Araras, Sorocaba e Lagoa do Sino SP.

Para que todas as possibilidades identificadas se concretizem, contudo, ainda há algumas dificuldades a serem superadas, a maioria delas recorrente quando se trata de inovação e implantação de novos projetos em bibliotecas universitárias. São elas a escassez de recursos financeiros e humanos e a resistência dos profissionais à mudança de cultura e à adoção de novas práticas. Há, ainda, um aspecto específico que exige atenção: a necessidade de elaboração de uma política com orientações e regras relativas aos novos usos da biblioteca.

Ao lançar luz sobre essas potencialidades e dificuldades da BU como mecanismo de geração de empreendimentos - a partir da experiência da BCo da UFSCar no Desafio UFSCar de Inovação e Empreendedorismo -, esperamos conscientizar outras BUs de sua capacidade de exercer essa nova função e inspirá-las a partir para a ação. Para auxiliá-las nesse processo, encerramos este artigo com algumas recomendações. Recomendamos a elas que se aproximem de incubadoras, aceleradoras, coworkings e laboratórios de prototipagem e que aprendam com eles. Indicamos, também, que estabeleçam parcerias e redes, que identifiquem e consolidem os diferenciais da biblioteca como mecanismo de geração de empreendimentos e que criem grupos internos de trabalho para a definição de estratégias junto às lideranças da universidade, a fim de assegurar recursos orçamentários para as iniciativas. Sugerimos que registrem e divulguem as ações de promoção da inovação e do empreendedorismo realizadas, visando institucionalizar a nova função da BU. Propomos, ainda, que estabeleçam métricas de avaliação e construam indicadores sobre essas ações. Por fim, recomendamos às bibliotecas universitárias que criem espaços para a troca de saberes e experiências com outras universidades e bibliotecas. 


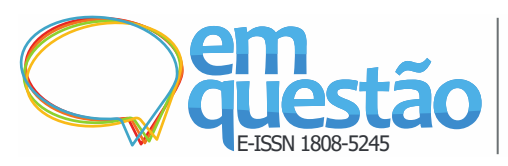

A biblioteca universitária como mecanismo híbrido de geração de empreendimentos: possibilidades rumo à universidade empreendedora

Maísa Maryelli de Oliveira, Camila Cassiavilani, Adriana Tahereh Pereira Spinola, Roniberto Morato do Amaral e Roberto Ferrari Junior

\section{Referências}

ARANHA, J. A. S. Mecanismos de geração de empreendimentos inovadores: mudança na organização e na dinâmica dos ambientes e o surgimento de novos atores. Brasília: ANPROTEC, 2016.

AUDY, J. L. N. Entre a tradição e a renovação: os desafios da universidade empreendedora. In: MOROSINI, M. (org.). 2 ed. A universidade no Brasil: concepções e modelos. Brasília: Instituto Nacional de Estudos e Pesquisas Educacionais Anísio Teixeira, 2011.

BARDIN, L. Análise de conteúdo. Lisboa: Edições 70, 1977.

BONTE, A. Was ist eine Bibliothek? Physische Bibliotheken im digitalen Zeitalter. ABI Technik, [s. l.], v. 35, n. 2, p. 95-104, 2015.

BRASIL. Decreto ${ }^{\circ} 9.283$, de 7 de fevereiro de 2018. Regulamenta a Lei ${ }^{\circ}$ 10.973, de 2 de dezembro de 2004, a Lei $n^{\circ} 13.243$, de 11 de janeiro de 2016, o art. $24, \S 3^{\circ}$, e o art. $32, \S 7^{\circ}$, da Lei ${ }^{\circ} 8.666$, de 21 de junho de 1993 , o art. $1^{\circ}$ da Lei $\mathrm{n}^{\circ} 8.010$, de 29 de março de 1990, e o art. $2^{\circ}$, caput, inciso I, alínea "g", da Lei $n^{\circ} 8.032$, de 12 de abril de 1990, e altera o Decreto ${ }^{\circ} 6.759$, de 5 de fevereiro de 2009, para estabelecer medidas de incentivo à inovação e à pesquisa científica e tecnológica no ambiente produtivo, com vistas à capacitação tecnológica, ao alcance da autonomia tecnológica e ao desenvolvimento do sistema produtivo nacional e regional. Diário Oficial da União. Brasília, 8 fev. 2018.

BRASIL. Lei $\mathrm{n}^{\circ}$ 13.243, de 11 de janeiro de 2016. Dispõe sobre estímulos ao desenvolvimento científico, à pesquisa, à capacitação científica e tecnológica e à inovação e altera a Lei $\mathrm{n}^{\mathrm{o}} 10.973$, de 2 de dezembro de 2004, a Lei $\mathrm{n}^{\circ}$ 6.815, de 19 de agosto de 1980, a Lei no 8.666, de 21 de junho de 1993, a Lei no 12.462, de 4 de agosto de 2011, a Lei ${ }^{\circ} 8.745$, de 9 de dezembro de 1993, a Lei ${ }^{\circ}$ 8.958, de 20 de dezembro de 1994, a Lei no 8.010, de 29 de março de 1990, a Lei $\mathrm{n}^{\circ} 8.032$, de 12 de abril de 1990, e a Lei $\mathrm{n}^{\circ} 12.772$, de 28 de dezembro de 2012, nos termos da Emenda Constitucional no 85, de 26 de fevereiro de 2015. Diário Oficial da União. Brasília, 12 jan. 2016.

CLARK, B. Creating entrepreneurial universities: organizational pathways of transformation. Oxford: Pergamon-Elsevier, 1998.

CLARK, B. Sustaining change in universities: continuities in case studies and concepts. Tertiary Education and Management, [s. l.], v. 9, n. 2, p. 99-116, 2003.

DYSART, J.; JONES, R. Innovative services in libraries. Computers in Libraries, Medford, v. 31, n. 5, p. 14-15, 2011. 


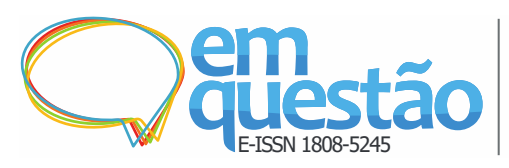

A biblioteca universitária como mecanismo híbrido de geração de empreendimentos: possibilidades rumo à universidade empreendedora

Maísa Maryelli de Oliveira, Camila Cassiavilani, Adriana Tahereh Pereira Spinola, Roniberto Morato do Amaral e Roberto Ferrari Junior

ETZKOWITZ, H. The norm of entrepreneurial science: cognitive effects of the new university-industry linkages. Research Policy, [s. l.], v. 27, n. 8, p. 823833, 1998.

EYCHENNE, F.; NEVES, H. Fab Lab: a vanguarda da nova revolução industrial. São Paulo: Editorial Fab Lab Brasil, 2013.

FREEMAN, C. Schumpeter's business cycles and techno-economic paradigms. In: DRECHSLER, W.; KATTEL, R.; REINERT, E. (org.). Techno-economic paradigms: essays in honour of Carlota Perez. London: Anthem, 2011.

GIL, A. C. Métodos e técnicas de pesquisa social. 6 ed. São Paulo: Atlas, 2010.

HARRIS, M. Technology, innovation and post-bureaucracy: the case of the British Library. Journal of Organizational Change Management, [s. l.], v. 19, n. 1, p. 80-92, 2006.

HOPPENFELD, J.; MALAFI, E. Engaging with entrepreneurs in academic and public libraries. Reference Services Review, [s. l.], v. 43, n. 3, p. 379-399, 2015.

JANSEN, S. et al. How education, stimulation, and incubation encourage student entrepreneurship: observations from MIT, IIIT, and Utrecht University. The International Journal of Management Education, [s. l.], v. 13, n. 2, p. 170-181, 2015.

JANTZ, R. C. Innovation in academic libraries: an analysis of university librarians' perspectives. Library \& Information Science Research, [s. l.], v. 34, n. 1, p. 3-12, 2012.

KATSIRIKOU, A.; SEFERTZI, E. Innovation in the everyday life of libraries. Technovation, [s. l. ], n. 20, v. 12, p. 705-709, 2000.

LASTRES, H. M. M.; FERRAZ, J. C. Economia da Informação, do Conhecimento e do Aprendizado. In: LASTRES, H. M. M.; ALBAGLI, S. (org.). Informação e globalização na era do conhecimento. Rio de Janeiro: Editora Campus, 1999.

MEDINA, P. F.; KRAWULSKI, E. Coworking como modalidade e espaço de trabalho: uma análise bibliométrica. Cadernos de Psicologia Social do Trabalho, [s. l.], v. 18, n. 2, p. 181, 31 dez. 2015.

MESQUITA, L. A. F. As práticas que sustentam o trabalho colaborativo em espaços de coworking e o papel das tecnologias de informação e comunicação: estudo de caso da Goma. 2016. Dissertação (Mestrado em 


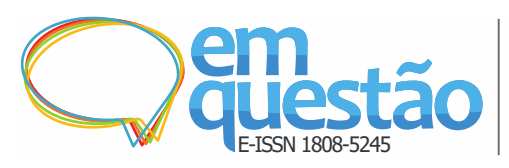

A biblioteca universitária como mecanismo híbrido de geração de empreendimentos: possibilidades rumo à universidade empreendedora

Maísa Maryelli de Oliveira, Camila Cassiavilani, Adriana Tahereh Pereira Spinola, Roniberto Morato do Amaral e Roberto Ferrari Junior

Administação de Empresas) - Escola de Administração de São Paulo, Fundação Getúlio Vargas, São Paulo, 2016.

NELSON, R. R. Technology, institutions, and economic development. In: DRECHSLER, W.; KATTEL, R.; REINERT, E. (org.). Techno-economic paradigms: essays in honour of Carlota Perez. London: Anthem, 2011.

ORGANISATION FOR ECONOMIC CO-OPERATION AND

DEVELOPMENT. The knowledge-based economy. Paris: OECD, 1996.

PINTO, S. L. U. et al. O movimento maker: enfoque nos fablabs

brasileiros. Revista Livre de Sustentabilidade e Empreendedorismo, [s. 1.] v. 3, n. 1, p. 38-56, 2018.

RESNICK, B. The Library of the Future Is Here. Citylab, 2014.

SCHUMPETER, J. A. Teoria do desenvolvimento econômico: uma

investigação sobre lucros, capital, crédito, juro e o ciclo econômico. São Paulo: Nova Cultural, 1997.

SCHOPFEL, J.; ROCHE, J.; HUBERT, G. Co-working and innovation: new concepts for academic libraries and learning centres. New Library World, $[s$. l.], v. 116, n. 1/2, p. 67-79, 2015.

YEH, S.T.; WALTER, Z. Determinants of service innovation in academic libraries through the lens of disruptive innovation. College and Research Libraries, [s. 1.], v. 77, n. 6, p. 795-804, 2016.

ZANINELLI, T. B.; NOGUEIRA, C. A.; PERES, A. L. M. Bibliotecas universitárias: uma perspectiva teórica sobre inovação em serviços informacionais. Revista Digital de Biblioteconomia e Ciência da Informação, [s. l.], v. 17, p. 1-20, 2019.

\title{
The academic library as a hybrid mechanism of enterprise generation: possibilities towards the entrepreneurial university
}

\begin{abstract}
This article discusses the potentialities and difficulties of the academic library as a hybrid mechanism of enterprise generation, capable of contributing to the transition to the entrepreneurial university, understood from an international model. The discussion is based on the participation of the Biblioteca Comunitária da Universidade Federal de São Carlos (UFSCar) ("Community Library of the Federal University of São Carlos") in the first
\end{abstract}




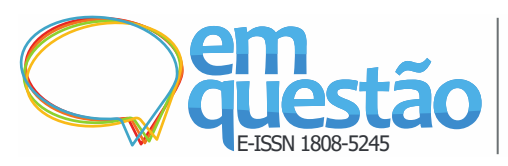

\section{A biblioteca universitária como mecanismo híbrido de geração de empreendimentos: possibilidades rumo à universidade empreendedora \\ Maísa Maryelli de Oliveira, Camila Cassiavilani, Adriana Tahereh Pereira Spinola, Roniberto Morato do Amaral e Roberto Ferrari Junior}

edition of the Desafio UFSCar de Inovação e Empreendedorismo (UFSCar Innovation and Entrepreneurship Challenge). This is an exploratory study which takes a qualitative approach and adopts a documentary research procedure. Although the UFSCar library's performance in the UFSCar Challenge had been restricted to the allocation of physical space, experience showed that, through adaptations in terms of infrastructure and management, that library, as well as the academic library in general, could incorporate elements of coworking and of prototyping laboratories, which would enable collaboration between potential entrepreneurs, would provide for networking and would make it possible to draw upon known tools and techniques for new business proposals. Furthermore, librarians could train future entrepreneurs to use technical and scientific databases, especially patent databases, which would enable them to search for precedence and would stimulate processes of competitive intelligence and technological mapping, considered crucial to the development of a business plan. Generally being a place where many people go to and where many people meet, the library could also help to disseminate a culture of innovation and entrepreneurship at the university, which would foster the appreciation of that institution and that of its professionals on campus. On the other hand, for all this to happen, some possible difficulties must be overcome, such as the scarcity of financial and human resources, the development of a library space usage policy, and professionals' resistance to culture change and to the adoption of new practices.

Keywords: Entrepreneurial university. Academic library. Academic entrepreneurship. Startup.

Recebido: 05/07/2019

Aceito: 10/12/2019

\footnotetext{
${ }^{1}$ Ao mesmo tempo que cita incubadoras, aceleradoras, espaços abertos de trabalho cooperativo e laboratórios abertos de prototipagem de produtos e processos como exemplos de mecanismos de geração de empreendimentos, o decreto traz a expressão "entre outros", sinalizando que há outros mecanismos possíveis. Neste artigo, defende-se que a biblioteca universitária pode ser um mecanismo de geração de empreendimentos.

${ }^{2}$ Aqui, o termo "incubação" sintetiza todas as etapas do processo: pré-incubação, incubação e graduação.

${ }^{3}$ Trata-se de uma máquina que tem movimentos controlados por um computador. Cortadoras a laser e impressoras 3D também são consideradas máquinas CNC. A fresadora CNC usa um método subtrativo para modelar a peça, esculpindo em uma chapa ou um bloco de material.

${ }^{4}$ Os conteúdos consultados podem ser acessados a partir do site da UFSCar: www.ufscar.br .

${ }^{5}$ A Agência de Inovação da UFSCar é um núcleo de inovação tecnológica (NIT). O NIT foi definido pela Lei $n^{\circ} 13.243$, de 11 de janeiro de 2016 - que altera a Lei $n^{\circ} 10.973$, de 2 de dezembro de 2004, conhecida como Lei de Inovação Tecnológica - como: “[...] estrutura instituída por uma ou mais ICTs, com ou sem personalidade jurídica própria, que tenha por finalidade a gestão de política institucional de inovação e por competências mínimas as atribuições previstas nesta Lei [...]” (BRASIL, 2016).
} 

geração de empreendimentos: possibilidades rumo à

6 O vencedor da categoria "startup" foi o doutorando do Departamento de Engenharia de Materiais (DEMa) da UFSCar Gustavo Valio. Ele apresentou uma solução tecnológica alternativa para o gesso ortopédico, a fim de melhorar a experiência de pacientes que necessitam de imobilização e facilitar o trabalho do profissional, eliminando a sujeira do ambiente e, praticamente, com o mesmo custo de processo. Na categoria "licenciamento", os vencedores foram Marina Trevelin e Clever Chinaglia, que construíram um modelo de negócios para uma de suas tecnologias desenvolvida dentro do Laboratório de Materiais Vítreos (LaMaV) da UFSCar e licenciada pela Vetra, empresa criada pelos próprios pesquisadores com o objetivo de comercializar biomateriais.

7 "No original: The library as a warehouse of information is an outdated concept. The library of the 21 st century is a community workshop, a hub filled with the tools of the knowledge economy.”. Documento eletrônico não paginado. 